\title{
Retrospective analysis of traumatic triradiate cartilage injury in children
}

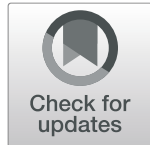

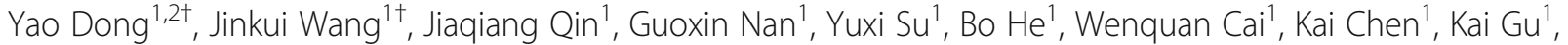 \\ Xun Liang ${ }^{1}$, Ge Yan ${ }^{1}$ and Zhongliang Wang ${ }^{1 *}$
}

\begin{abstract}
Background: To summarize and analyze the epidemiological characteristics, treatment and corresponding curative effect of triradiate cartilage injury $(\mathrm{TCl})$ in children after trauma, to provide a theoretical basis for early diagnosis and improvement of treatment.

Methods: The TCI was classified according to Bucholz classification, and the final curative effect was evaluated with Harris Hip Score and imaging examination during follow-up. Finally, a comprehensive analysis was made by reviewing the cases in the literature combined with the patients in our hospital.

Results: A total of 15 cases (18 hips) of triradiate cartilage injuries were collected in our hospital. There was 1 hip with type I injury, nine hips with type II injury, two hips with type IV injury, one hip with type V injury and five hips with type $\mathrm{VI}$ injury. Among the 12 cases with complete follow-up, the bone bridge was found in or around the triradiate cartilage in 8 cases, early fusion of triradiate cartilage occurred in 5 patients, 3 cases had hip dysplasia, 4 cases had a subluxation of the femoral head, and HHS was excellent in 8 cases and good in 4 cases.

Conclusion: The early diagnosis of $\mathrm{TCl}$ is still a difficult problem. Conservative treatment is often the first choice. The overall prognosis of acetabular fractures involving triradiate cartilage is poor. The formation of the bone bridge in triradiate cartilage usually indicates the possibility of premature closure, which may lead to severe complications of post-traumatic acetabular dysplasia and subluxation of the femoral head.
\end{abstract}

Keywords: Pelvic fracture, Triradiate cartilage, Injury, Diagnosis, Treatment, Acetabular dysplasia

\section{Introduction}

Triradiate cartilage is located between the ilium, pubis and ischium. Its branches are arranged like a Y-shape, namely the iliopubic arm, iliosciatic arm, and ischiopubic arm. Different from the growth structure of long bones, each triradiate cartilage has bone growth plates on both

\footnotetext{
* Correspondence: 4829855@163.com

${ }^{\dagger}$ Yao Dong and JinKui Wang contributed equally to this work and should be considered co-first authors.

'Department of Orthopedics; Ministry of Education Key Laboratory of Child Development and Disorders, National Clinical Research Center for Child Health and Disorders (Chongqing), China International Science and Technology Cooperation base of Child development and Critical Disorders, Chongqing Key Laboratory of Pediatrics, Children's Hospital of Chongqing Medical University, 2 ZhongShan Rd, 400013 Chongqing, P.R. China Full list of author information is available at the end of the article
}

sides, and the central zone is the secondary ossification centre, so it grows bipolar(Fig. 1). Triradiate cartilage can be divided into germinal area and hypertrophy zone. The germinal area has a large blood supply and is surrounded by a hypertrophic zone [1,2]. The secondary ossification centre of the Triradiate cartilage usually appears around ten years old and closes at 14 years old, marking the end of acetabular development [3]. Triradiate cartilage is the main structure that determines the development of the acetabulum. The interstitial growth of the triradiate cartilage and the additional expansion of the peripheral perichondrium lead to the increase in the volume, width and height of the acetabulum. Intrachondral osteogenesis promotes the continuous growth and

(c) The Author(s). 2021 Open Access This article is licensed under a Creative Commons Attribution 4.0 International License, which permits use, sharing, adaptation, distribution and reproduction in any medium or format, as long as you give appropriate credit to the original author(s) and the source, provide a link to the Creative Commons licence, and indicate if changes were made. The images or other third party material in this article are included in the article's Creative Commons licence, unless indicated otherwise in a credit line to the material. If material is not included in the article's Creative Commons licence and your intended use is not permitted by statutory regulation or exceeds the permitted use, you will need to obtain permission directly from the copyright holder. To view a copy of this licence, visit http://creativecommons.org/licenses/by/4.0/ The Creative Commons Public Domain Dedication waiver (http://creativecommons.org/publicdomain/zero/1.0/) applies to the data made available in this article, unless otherwise stated in a credit line to the data. 


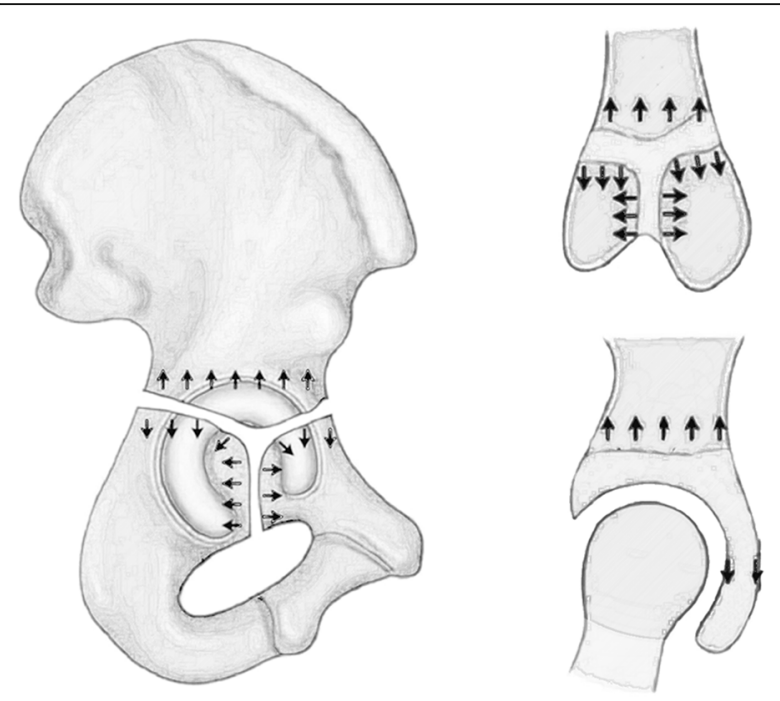

Fig. 1 Schematic diagram of triradiate cartilage growth. The direction arrow shows the development of triradiate cartilage

closure of these epiphyses $[1,2,4,5]$. Severe Triradiate cartilage injury(TCI) will directly affect the growth and development of the acetabulum, leading to acetabular dysplasia.

TCIs often occur in high-energy pelvic injuries [6]. Acetabular fractures account for $0.8 \sim 15.2 \%$ of children's fractures, of which about $0 \sim 11 \%$ involve cartilage $[1,6$, 7]. TCI is relatively insidious, and early diagnosis is rugged and easy to miss. The current literature on TCI is mostly case reports, and its epidemiological characteristics, degree of injury, type of injury, and treatment plan are unclear. Both surgical treatment and conservative treatment are advocated. The common goal is to restore the anatomy while avoiding further damage to the triradiate cartilage blood supply, to reduce the occurrence of complications such as acetabular dysplasia and femoral head subluxation [8]. We review the literature and summarize the TCI cases in our hospital, aiming to provide experience for the early diagnosis and treatment of TCI.

\section{Result}

From January 2010 to December 2017, a total of 191 children with pelvic fractures were admitted to our hospital. Among them, 24 children (12.57\%) with acetabular fractures, 15 children (7.85\%) with Triradiate cartilage injuries. These children with TCI, only 8 cases were diagnosed early, four cases were diagnosed during followup, and 3 cases were found during the review. Among the 15 children, 10 were males, and 5 were females, ranging from 1.4 to 9.8 years old, with an average of 5.6 years old. Among them, 4 cases were under 3 years old, 5 cases were 3 to 6 years old, and 7 cases were over 6 years old. There were 12 cases of traffic accident injuries,
2 cases of crush injuries, and 1 case of fall injuries. Among the 15 children, 3 cases involved bilateral triradiate cartilage, and 6 cases of unilateral injury, totalling 18 hips. One hip with type I injury, nine hips with type II injury, and one hip with type V injury. Seven hips cannot be classified according to the Bucholz classification, of which two hips are fracture lines that entirely through the triradiate cartilage and involve the metaphyses on both sides, similar to type IV epiphyseal injuries; 5 hips are fractures of the proximal suprapubic branch, the imaging examination did not show the triradiate cartilage involved, but in the later follow-up, it was found that the bone bridge was formed inside the triradiate cartilage, we tentatively determined it as a type VI injury. There were 7 cases with severe joint dislocation, including 3 cases with pubic symphysis diastasis(PSD), 4 cases with sacroiliac joint dislocation(SIJD), and 1 case with PSD and SIJD. Eight patients with TCI were treated conservatively, including bed rest, external brace fixation, lower extremity skin traction, and then gradually bearing weight. Seven children with severe pelvic fractures were treated with closed reduction and external stent fixation or open reduction and internal fixation(ORIF).

During the follow-up, two of the children had undergone high amputation due to severe damage to their lower limbs, and the parents were unwilling to cooperate with the follow-up, one child lost to follow-up. A total of 12 children were followed up. The follow-up time was 1.5 to 7.8 years, with an average of 5 years. The general information on admission of the children is shown in Table 1. The hip function of children was based on HHS (excellent 91-100; good 81-90; fair 71-80; poor 70 or less). Among the 12 children followed up, 8 cases were excellent, and 4 cases were good. The follow-up results are shown in Table 2. The AI, D/W, and AHI were measured by pelvic X-rays to assess the development of the acetabulum and the subluxation of the femoral head. Eight cases had bone bridges formed around triradiate cartilage, and 5 cases had triradiate cartilage premature closure, 2 cases had acetabular dysplasia, and 4 cases had femoral head subluxation.

\section{Typical cases \\ Case 1(patient A)}

A 6-year-old girl suffered a pelvic fracture after being hit by a car. CT examination showed multiple fractures of the pelvis, bilateral acetabular fractures, separation of the pubic symphysis, and sacral fractures. Triradiate cartilage on the right is a type I injury, and the left is type II injury(Fig. 2A). Closed reduction and external stent fixation were performed after the vital signs were stable(Fig. 2B). Two months after the operation, the pelvis gradually bears weight. Follow-up 17 months after the operation, the child had mild claudication, no hip joint 
Table 1 General data of 12 children with Triradiate cartilage injury

\begin{tabular}{|c|c|c|c|c|c|c|c|}
\hline Case & Sex & Age & Side & Type & Location & Complications & Treatment \\
\hline A & $\mathrm{F}$ & $6 y$ & $L / R$ & $\| / /$ & $\begin{array}{l}\text { Left iliopubic branch, } \\
\text { Right pubis }\end{array}$ & PSD & Closed reduction and external stent fixation \\
\hline B & M & $6.2 y$ & L & $\mathrm{Vl}$ & Suprapubic branch & SIJD & Closed reduction and external stent fixation \\
\hline C & M & $1.4 y$ & $\mathrm{R}$ & $\mathrm{Vl}$ & Suprapubic branch & No & External brace fixation \\
\hline D & $\mathrm{F}$ & $3 y$ & $L / R$ & $\mathrm{VI} / \mathrm{VI}$ & Suprapubic branch & No & Lower limb traction +External brace fixation \\
\hline E & M & $5.1 y$ & $\mathrm{R}$ & IV & Iliosciatic branch & No & Lower limb traction + External brace fixation \\
\hline $\mathrm{F}$ & $\mathrm{F}$ & $2.3 y$ & $L / R$ & $\|/\|$ & $\begin{array}{l}\text { Bilateral } \\
\text { ischiopubicbranch }\end{array}$ & PSD & Closed reduction and external stent fixation \\
\hline G & M & $4 y$ & L & V & Left iliosciaticbranch & No & External brace fixation \\
\hline $\mathrm{H}$ & M & $5 y$ & L & $\|$ & ischiopubicbranch & SIJD & Closed reduction and external stent fixation \\
\hline । & M & $2.2 y$ & $\mathrm{R}$ & $\|$ & ischiopubicbranch & PSD & Closed reduction and external stent fixation \\
\hline J & M & $8.5 y$ & $\mathrm{R}$ & $\|$ & ischiopubicbranch & No & Lower limb traction +External brace fixation \\
\hline K & $\mathrm{F}$ & $8.8 y$ & L & $\|$ & $\begin{array}{l}\text { Iliosciatic } \\
\text { branch }\end{array}$ & $\mathrm{PSD} / \mathrm{SIJD}$ & ORIF of $L$ sacroiliac joint and symphysis pubis \\
\hline L & $\mathrm{F}$ & $7.8 y$ & $\mathrm{R}$ & $\|$ & Iliopubic branch & No & External brace fixation \\
\hline M & M & $5.4 y$ & $\mathrm{R}$ & $\|$ & ischiopubicbranch & No & External brace fixation \\
\hline N & M & $7.9 y$ & L & $\mathrm{Vl}$ & Suprapubic branch & No & Open reduction and external stent fixation + amputation \\
\hline $\mathrm{O}$ & M & $9.8 y$ & L & IV & ischiopubicbranch & SIJD & $\begin{array}{l}\text { External brace fixation }+ \text { Open reduction and external stent fixation }+ \\
\text { amputation of pelvic fracture }\end{array}$ \\
\hline
\end{tabular}

ORIF Open reduction and internal fixation, PSD Pubic Symphysis Diastasis, SIJD Sacroiliac Joint Dislocation, $L$ Left, $R$ Right, $M$ Male, $F$ Female;

pain, and the HHS was excellent. X-rays of the pelvis showed that the pelvis was slightly tilted and the triradiate cartilage was partially closed, but the acetabulum and femoral head contained a good relationship(Fig. 2C).

\section{Case 2(patient C)}

A 1.4-year-old boy was hit by a car, resulting in a fractured pelvis, a fractured femur, and an abdominal injury. $\mathrm{X}$-ray and CT examination of the pelvis revealed fractures of the upper and lower branches of the right pubic bone and the right ischia(Fig. 3A-B). Treatment includes bed rest, brace fixation of the lower limbs and pelvis. Two weeks later, the X-ray showed the formation of a hematoma at the fracture of the right suprapubic ramus and the formation of a bone bridge across the medial edge of the triradiate cartilage, and was classified as type VI TCI(Fig. 3C). Five months later, the original bone bridge was found to be broken(Fig. 3D). We believe that the fracture of the bone bridge will not further affect the development of the acetabulum, so we choose to continue conservative treatment. Seven years later, the child had mild pain in the right hip, no claudication, and an

Table 2 fallow-up of 12 children with Triradiate cartilage injury

\begin{tabular}{|c|c|c|c|c|c|c|c|c|c|}
\hline Case & Follow-up(mo) & Bone bridge & Premature closure & $\begin{array}{l}\text { Acetabular } \\
\text { dysplasia }\end{array}$ & Femoral head subluxation & HHS & $\mathrm{Al}\left({ }^{\circ}\right)(\mathrm{L} / \mathrm{R})$ & $\mathrm{D} / \mathrm{W}(\mathrm{L} / \mathrm{R})$ & $\mathrm{AHI}(\mathrm{L} / \mathrm{R})$ \\
\hline A & 17 & yes & yes & no & no & excellet & $16 / 10$ & $0.324 / 0.38$ & $1 / 1$ \\
\hline B & 66 & yes & no & no & no & excellet & $8 / 22$ & $0.359 / 0.319$ & $0.93 / 0.96$ \\
\hline C & 77 & yes & no & yes & yes & excellet & $19 / 12$ & $0.3 / 0.216$ & $0.856 / 0.695$ \\
\hline D & 32 & yes & no & no & no & excellet & $27 / 25$ & $0.266 / 0.288$ & $0.795 / 0.81$ \\
\hline$E$ & 56 & no & no & yes & no & good & $15 / 20$ & $0.281 / 0.247$ & $1 / 1$ \\
\hline $\mathrm{F}$ & 94 & no & no & no & no & excellet & $21 / 21$ & $0.286 / 0.288$ & $1 / 1$ \\
\hline G & 71 & yes & yes & yes & yes & good & $27 / 21$ & $0.214 / 0.26$ & $0.62 / 0.844$ \\
\hline $\mathrm{H}$ & 34 & yes & yes & no & yes & excellet & $23 / 13$ & 0.336/0.294 & $0.64 / 1$ \\
\hline I & 80 & no & no & no & no & excellet & $24 / 19$ & $0.323 / 0.332$ & $1 / 1$ \\
\hline J & 78 & yes & yes & no & yes & good & $17 / 19$ & $0.3 / 0.26^{*}$ & $0.77 / 0.67$ \\
\hline K & 80 & yes & yes & no & no & good & $8 / 18$ & $0.344 / 0.327$ & $0.871 / 0.755$ \\
\hline L & 36 & no & no & no & no & excellet & $22 / 14$ & $0.306 / 0.313$ & $1 / 1$ \\
\hline
\end{tabular}




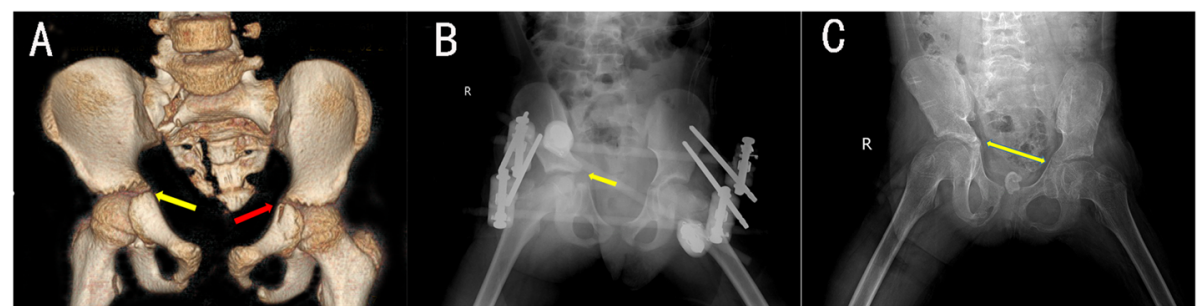

Fig. 2 A 6-year-old girl (case A); Three-dimensional CT imaging of the pelvis revealed that the left suprapubic ramus fracture involved Y-shaped cartilage (red arrow), and the right Y-shaped cartilage gap widened (yellow arrow) (A); The postoperative X-ray showed that the pelvis was fixed with Orthofix external stent, and the right Y-shaped cartilage gap was still significantly widened (yellow arrow) (B). Seventeen months after the operation, the X-ray showed that the Y-shaped cartilage was partially closed (C)

excellent HHS score. An X-ray showed that the bone bridge was broken, the inner wall of the right acetabulum became thick, the acetabulum became shallow, and the femoral head shifted to the outside(AI $12^{\circ}, \mathrm{D} / \mathrm{W}$ 0.216, AHI 0.683)(Fig. 3E).

\section{Case 3(patient E)}

A 5.1-year-old boy was crushed by a car and caused a pelvic fracture involving right ilium and right acetabulum fractures, and a fracture of the left femur neck. CT showed a fracture line from the iliac metaphyseal through the triradiate cartilage to the ischiadic metaphyseal and was classified as type IV TCI(Fig. 4A,B). After the essential condition is stable, the right femur neck was performed ORIF(Fig. 4C). One year later, MRI showed partial necrosis and collapse of the femoral head, with the triradiate cartilage had no bone bridge formation(Fig. 4D). Four years after the operation, the patient had mild claudication with dysfunction such as squatting and stocking. X-ray showed slightly oblique acetabulum and necrosis of femoral head.

\section{Methods}

We collected children with TCI admitted to the Children's Hospital of Chongqing Medical University from January 2010 to December 2017. This research was approved by the Ethics Review Board of the Children's Hospital of Chongqing Medical University. All patients or their relatives provided written informed consent to be included in this study. Inclusion criteria: 1)triradiate cartilage was not closed at the time of injury; 2)TCI after trauma (widening, narrowing, rupture, premature closure and bone bridge formation after injury); 3)Follow-up time $\geq 12$ months. We collect their general information (age, gender, injury location), physical examination, imaging data, and treatment methods of these children. The children were followed up regularly, including hip joint pain, claudication, daily life and sports, hip joint

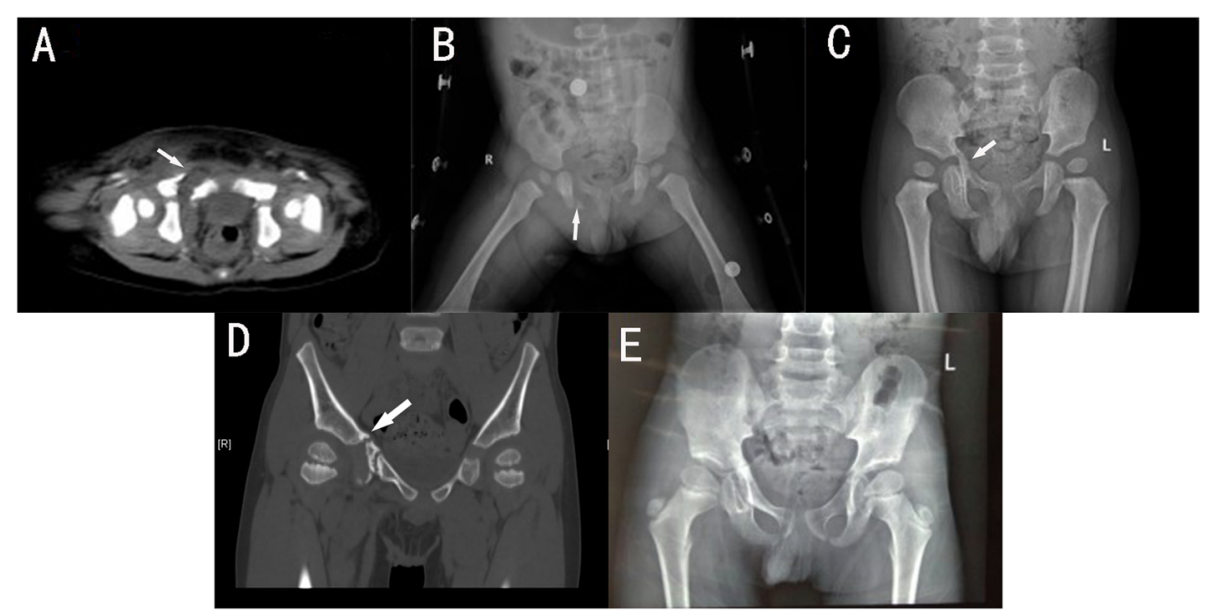

Fig. 3 A 1.4-year-old boy (case C). X-ray and CT suggests fractures of superior and inferior ramus of pubis and right ischium (white arrow) (A, B). Two weeks later, $\mathrm{X}$-ray showed a faint bony bridge formation across the medial margin of the triradiate cartilage on the right acetabulum (C) (white arrow). Five months after the injury, X-ray showed rupture of the original bone bridge (white arrow) (D). Seven years after injury, X-ray showed that the triradiate cartilage remained open, but the medial wall of the right acetabulum had thickened, the acetabulum had become shallow, and the femoral head had shifted slightly laterally (E) 


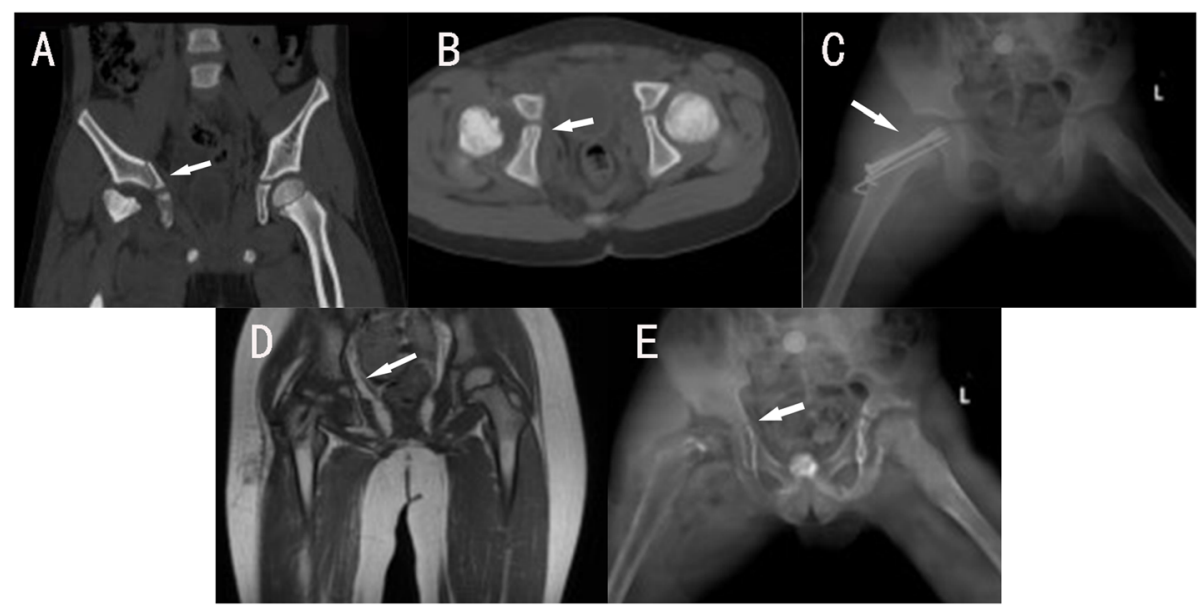

Fig. 4 A 5.1-year-old boy(case E) was crushed by a car and caused a pelvic fracture involving right ilium and right acetabulum fractures, and a fracture of the left femur neck. CT showed a fracture line from the iliac metaphyseal through the triradiate cartilage to the ischiadic metaphyseal and was classified as type IV TCI (A, B) (white arrow). After the essential condition is stable, the right femur neck was performed ORIF (C). One year later, MRI showed partial necrosis and collapse of the femoral head, with the triradiate cartilage had no bone bridge formation (D). Four years after the operation, the patient had mild claudication with dysfunction such as squatting and stocking. X-ray showed slightly oblique acetabulum and necrosis of femoral head (E)

range of motion, lower limb length, and pelvic tilt. Some children with X-ray, Computerized Tomography $(\mathrm{CT})$ or Magnetic Resonance Imaging(MRI) examination to understand the development of acetabulum and TCI.

Bucholz et al. classified TCI according to the SalterHarris epiphyseal injury classification [1], and we also made a preliminary classification of TCI. We evaluated the hip joint function of the child at the latest follow-up based on the Harris hip score(HHS). We assessed the development of the acetabulum by measuring the Acetabular Index (AI) and the Depth-to-Width ratio (D/W) of the acetabulum. We evaluated the subluxation of the hip by using the Head of Acetabular Index (AHI) (AI greater than $30^{\circ}$ or $\mathrm{D} / \mathrm{W}$ less than 0.25 is considered acetabular dysplasia; AHI less than 0.75 is deemed to be hip subluxation).

\section{Discussion}

TCI in children is rare, mostly in case reports. We use "pelvic fracture" and "child" and "triradiate cartilage" or "Y cartilage" or "growth plate" or "acetabular fracture" as the keyword to review all English articles on traumatic triradiate cartilage injuries in children. We found 12 articles in total, including 29 cases, 17 males and 12 females, with an average age of 7 years old. Among them, 20 cases have a reliable classification, including 4 cases of type I, 4 cases of type II, 6 cases of type V, and 6 cases of type $\mathrm{VI}$ (which are classified as type $\mathrm{V}$ initially). Most of them received conservative treatment, and only four children underwent bone bridge resection, of which 2 had no hip pain and no acetabular dysplasia. Twentynine children were followed up for an average of 7 years.
In 12 cases, bone bridges across triradiate cartilage were formed in the early post-injury period, appears as early as 6 weeks after injury. Nine cases had triradiate cartilage epiphysis premature closure. Acetabular dysplasia occurred in 12 cases, and 11 cases showed hip subluxation. There were also complications such as hip pain, lower limb shortening, claudication, pelvic tilt, and pelvic dysplasia (Table 3). Among children with TCI in our hospital, type II injury is the most common, but type V is the most common type reported in previous literature. It may be due to the advancement of modern medical imaging technology that fracture fragments are easier to find.

\section{Classification of TCI}

The Bucholz classification of TCI is based on the SalterHarris epiphyseal classification, which is divided into I, II, and V types [1]. However, in the case of our hospital, it was found that two injuries could not be classified according to the Bucholz classification, so we propose a modified Bucholz classification(Fig. 5). The two new injury types are defined as type IV and type VI respectively; type IV is a fracture that penetrates the triradiate cartilage and the metaphysis on both sides, which is caused by vertical shear force. Type VI is a bone bridge formed by a hematoma caused by a fracture of the suprapubic branch, which was reported in several cases in the previous literature (6/29). However, they are all classified as type $\mathrm{V}$. We believe that the formation of type VI bone bridge is different from type V injury in that it is formed outside instead of inside the triradiate cartilage [4]. 


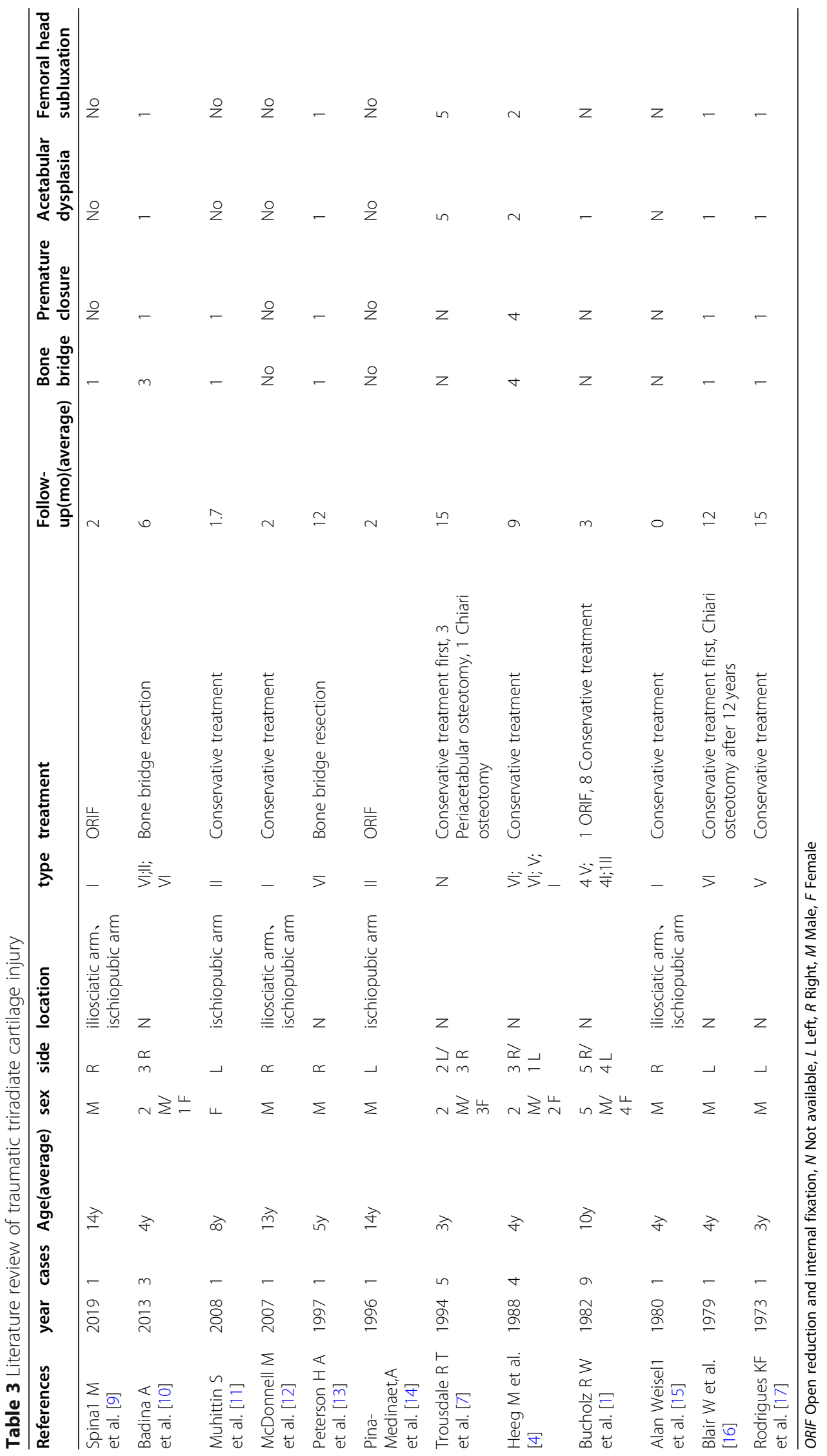



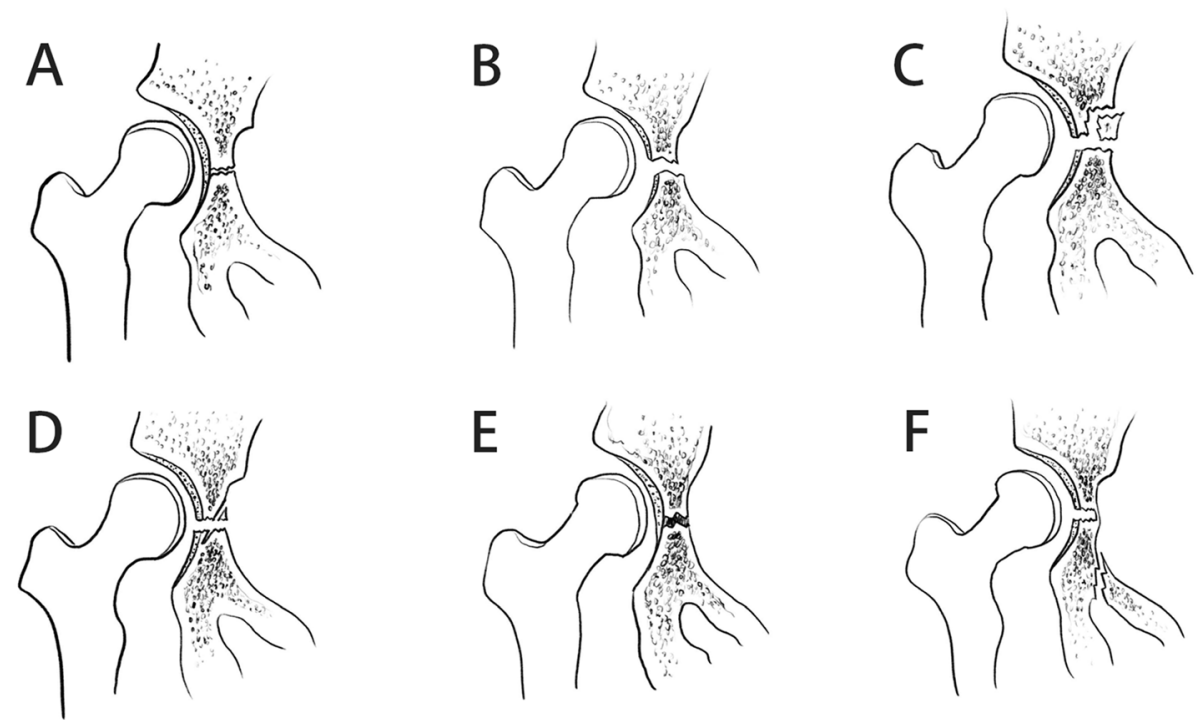

Fig. 5 Modified Bucholz classification. A Normal, B Type I, C Type II, D Type IV, E Type V, F type VI

\section{Diagnosis of $\mathrm{TCl}$}

TCI mostly occur in high-energy traumas such as car accident injuries and fall injuries, and most of them are children under ten years old. Du to triradiate cartilage gradually begins to ossify and fuse after ten years of age. More than $50 \%$ of triradiate cartilage injuries are missed in the initial diagnosis. The first missed diagnosis rate of the cases in this study is as high as $46.7 \%[4,11]$. Therefore, the imaging performance of TCI is essential. TCI can be manifested as widening or narrowing of the triradiate cartilage gap, small bone fragments at the iliac, pubic, and ischial metaphysis, and changes in the relationship between the ilium, ischium, and pubis. After the injury, bone bridges formation, triradiate cartilage ossification, and premature closure will be seen in TCI. TCI can be detected by X-ray if the fracture has significant displacement, such as type II or type IV. If fracture displacement is not obvious, most TCI can be detected by 3D reconstruction CT. Type I and V TCI without significant displacement may make it difficult to confirm the diagnosis. MRI of the hip joint is recommended to confirm the presence of TCI. Besides, MRI can clearly distinguish the size of the hematoma formed around the triradiate cartilage in the early stage, to predict the size of the bone bridge formation, and provide evidence for whether to perform bone bridge resection. In addition, Children with suspected TCI, who cannot be identified by radiographic examination but is accompanied by pelvic or acetabular injury, should be followed up for at least 1 year. Those who are diagnosed with TCI should be followed up until the bones mature.

\section{Treatment of TCl}

Due to the unique development of children's acetabulum, TCI requires individualized treatment. Both surgical treatment and conservative treatment have been reported. For unstable pelvic fractures and acetabular fractures, regardless of whether it is combined with TCI, active ORIF is recommended, which is very helpful to restore the anatomical structure of the pelvis and reduce complications $[18,19]$. Most patients in the previous literature have received conservative treatment, includes bed rest and skeletal traction for 4 to 8 weeks [7]. Some authors believe that the bone bridge at the triradiate cartilage should not be treated by surgery because the location is difficult to access, and the operation may cause damage to surrounding structures [11]. Another objection to surgical treatment is that the bone bridge formed after trauma may be too large to be removed, and even after the removal, the bone bridge may still be constructed again [13]. In our case series, the degree of displacement of the acetabular fracture in children was light, and the integrity of the acetabular joint surface was maintained well. All children were treated conservatively. Two children with a small bone bridge ruptured spontaneously after 2 to 4 months. No evident acetabular dysplasia was found in the follow-up. One case with a large bone bridge broke spontaneously 5 months after the injury. However, in the later follow-up, it was found that the inner wall of the acetabulum gradually thickened, the acetabulum became shallow, and the femoral head subluxation.

We believe that the displacement greater than $2 \mathrm{~mm}$ or type VI triradiate cartilage injury should be treated with ORIF; other types of injuries can be treated 
conservatively. All children should be followed up until the triradiate cartilage is closed. Those with acetabular dysplasia should undergo pelvic osteotomy as soon as possible to improve the shape of the acetabulum and avoid the occurrence of osteoarthritis. When a bone bridge appears during follow-up, it should be determined whether to perform bone bridge resection based on factors such as the age of the child, the size of the bone bridge, and the degree of acetabular development. The age of the child is the most important influencing factor for acetabular dysplasia because the younger the generation indicates the more potential for growth of triradiate cartilage, which can cause acetabular dysplasia [12].

\section{Conclusion}

Early diagnosis of TCI in children is quite difficult. For suspected cases, the multi-angle hip joint X-ray and CT three-dimensional reconstruction should be perfected. If necessary, MRI should be performed. For patients with clear indications for acetabular fracture surgery or type VI TCI, ORIF should be actively performed. Conservative treatment is often recommended for most triradiate cartilage injuries. The prognosis of TCI is often poor. Age, injury location, and degree of injury are important factors affecting the prognosis. Children with TCI should be followed up until the bones mature.

\section{Abbreviations}

TCl: Triradiate cartilage injury; Al: Acetabular Index; AHI: Acetabular Head Index; D/W: Depth-to-width Ratio; HHS: Harris Hip Score; PSD: Pubic Symphysis Diastasis; SIJD: Sacroiliac Joint Dislocation

\section{Acknowledgements}

Not applicable.

\section{Authors' contributions}

The authors made the following contributions: YD, JKW and ZLW designed the study; ZLW, YD, and JKW conceived and designed the study. YD, JKW, $K G, X L$, and $G Y$ measured and recorded the data. JKW and YD wrote the paper. KC, WQC, and $\mathrm{BH}$ review the literature. JQQ, GXN, YXS, and ZLW reviewed and edited the manuscript. All authors read and approved the manuscript.

\section{Funding}

No funding was obtained for this study.

\section{Availability of data and materials}

All data generated or analysed during this study are included in this published article.

\section{Declarations}

\section{Ethics approval and consent to participate}

Our research was approved by the Ethics Review Board of the Children's Hospital of Chongqing Medical University. Written informed consent was obtained for the study from the parents of the patients. We also followed the Declaration of Helsinki and relevant policies in China.

\section{Consent for publication}

Not Applicable.

\section{Competing interests}

The authors declare that they have no competing interests.

\section{Author details}

'Department of Orthopedics; Ministry of Education Key Laboratory of Child Development and Disorders, National Clinical Research Center for Child Health and Disorders (Chongqing), China International Science and Technology Cooperation base of Child development and Critical Disorders, Chongqing Key Laboratory of Pediatrics, Children's Hospital of Chongqing Medical University, 2 ZhongShan Rd, 400013 Chongqing, P.R. China.

2Department of Orthopedics, The First People's Hospital of Ziyang, Sichuan, P.R. China.

Received: 15 April 2021 Accepted: 2 August 2021

Published online: 10 August 2021

\section{References}

1. Bucholz RW, Ezaki M, Ogden JA. Injury to the acetabular triradiate physeal cartilage. J Bone Joint Surg Am. 1982;64(4):600-9. https://doi.org/10.2106/ 00004623-198264040-00018.

2. Ponseti IV. Growth and development of the acetabulum in the normal child. Anatomical, histological, and roentgenographic studies. J Bone Joint Surg Am. 1978;60(5):575-85. https://doi.org/10.2106/00004623-19786005000001.

3. Parvaresh KC, Pennock AT, Bomar JD, Wenger DR, Upasani W. Analysis of acetabular ossification from the Triradiate cartilage and secondary centers. Pediatr Orthop. 2018;38(3):e145-50. https://doi.org/10.1097/BPO 0000000000001120

4. Heeg M, Visser JD, Oostvogel HJ. Injuries of the acetabular triradiate cartilage and sacroiliac joint. J Bone Joint Surg (Br). 1988;70(1):34-7.

5. Scuderi G, Bronson MJ. Triradiate cartilage injury. Report of two cases and review of the literature. Clin Orthop Relat Res. 1987;(217):179-89.

6. Smith WR, Oakley M, Morgan SJ. Current issues: pediatric pelvic fractures. J Pediatr Orthop. 2004;24(1):130-5. https://doi.org/10.1097/01241398-200401 000-00023.

7. Trousdale RT, Ganz R. Posttraumatic acetabular dysplasia. Clin Orthop Relat Res. 1994;(305):124-32

8. Liporace FA, Ong B, Mohaideen A, Ong A, Koval KJ. Development and injury of the triradiate cartilage with its effects on acetabular development: review of the literature. J Trauma. 2003;54(6):1245-9. https://doi.org/10.1097/01.TA. 0000029212.19179.4A.

9. Spina M, Luppi V, Chiappi J, Bagnis F, Rocca G. Triradiate cartilage fracture of the acetabulum treated surgically. Acta Biomed. 2019;90(1):116-21Published 2019 Jan 18. https://doi.org/10.23750/abm.v90i1.7263.

10. Badina A, Vialle R, Fitoussi F, Damsin JP. Case reports: treatment of traumatic triradiate cartilage epiphysiodesis: what is the role of bridge resection? Clin Orthop Relat Res. 2013;471(11):3701-5. https://doi.org/10.1007/s11999-013-3 054-z.

11. Sener M, Karapinar H, Kazimoglu C, Yagdi S, Akgun U. Fracture dislocation of sacroiliac joint associated with triradiate cartilage injury in a child: a case report. J Pediatr Orthop B. 2008;17(2):65-8. https://doi.org/10.1097/bpb. ob013e3282f34d44.

12. McDonnell M, Schachter AK, Phillips DP, Liporace FA. Acetabular fracture through the triradiate cartilage after low-energy trauma. J Orthop Trauma. 2007:21(7):495-8. https://doi.org/10.1097/BOT.0b013e31812f67ff.

13. Peterson HA, Robertson RC. Premature partial closure of the triradiate cartilage treated with excision of a physical osseous bar. Case report with a fourteen-year follow-up. J Bone Joint Surg Am. 1997;79(5):767-70. https:// doi.org/10.2106/00004623-199705000-00019.

14. Pina-Medina A, Pardo-Montaner J. Triradiate cartilage fracture associated with a transepiphyseal separation of the femoral head: a case report. J Orthop Trauma. 1996;10(8):575-7. https://doi.org/10.1097/00005131-199611 000-00012.

15. Weisel A, Hecht HL. Occult fracture through the triradiate cartilage of the acetabulum. AJR Am J Roentgenol. 1980;134(6):1262-4. https://doi.org/1 0.2214/ajr.134.6.1262.

16. Blair W, Hanson C. Traumatic closure of the triradiate cartilage: report of a case. J Bone Joint Surg Am. 1979;61(1):144-5. https://doi.org/10.2106/00004 623-197961010-00028.

17. Rodrigues KF. Injury of the acetabular epiphysis. Injury. 1973;4(3):258-60 https://doi.org/10.1016/0020-1383(73)90048-x. 
18. Karunakar MA, Goulet JA, Mueller KL, Bedi A, Le TT. Operative treatment of unstable pediatric pelvis and acetabular fractures. J Pediatr Orthop. 2005; 25(1):34-8. https://doi.org/10.1097/00004694-200501000-00009.

19. Magu NK, Gogna P, Singh A, Singla R, Rohilla R, Batra A, et al. Long term results after surgical management of posterior wall acetabular fractures. J Orthop Traumatol. 2014;15(3):173-9. https://doi.org/10.1007/s10195-014-02 97-8.

\section{Publisher's Note}

Springer Nature remains neutral with regard to jurisdictional claims in published maps and institutional affiliations.

Ready to submit your research? Choose BMC and benefit from:

- fast, convenient online submission

- thorough peer review by experienced researchers in your field

- rapid publication on acceptance

- support for research data, including large and complex data types

- gold Open Access which fosters wider collaboration and increased citations

- maximum visibility for your research: over $100 \mathrm{M}$ website views per year

At $\mathrm{BMC}$, research is always in progress.

Learn more biomedcentral.com/submissions 